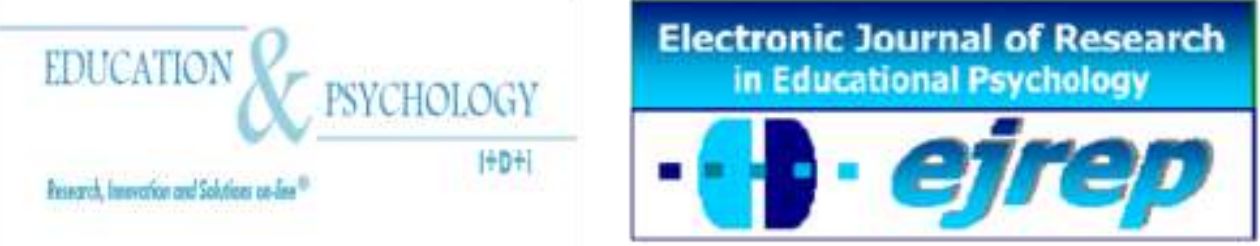

\title{
Internal and External Regulation to Support Knowledge Construction and Convergence in Computer Supported Collaborative Learning (CSCL)
}

\author{
Margarida Romero ${ }^{1}$, Niki Lambropoulos ${ }^{2}$ \\ ${ }^{1}$ Esade \& Universitat Autònoma de Barcelona \\ ${ }^{2}$ Department of Informatics, London South Bank University, London
}

Spain

United Kingdom

Correspondence: Dra. Margarida Romero. UAB, G6, Ciències de l'Educació, D.252. B 08193 Bellaterra (Cerdanyola del Vallès). SPAIN. Email: margarida.romero@uab.cat

(C) Education \& Psychology I+D + i and Editorial EOS (Spain) 


\begin{abstract}
Computer Supported Collaborative Learning (CSCL) activities aim to promote collaborative knowledge construction and convergence. During the CSCL activity, the students should regulate their learning activity, at the individual and collective level. This implies an organisation cost related to the coordination of the activity with the team-mates and the internal and external regulation of this activity. Therefore, we consider a knowledge perspective and an organisation load perspective in the execution of the CSCL activities. We assume the time and efforts spent in the organisation are not spent in the knowledge construction and convergence process. Nevetheless, we assume that in CSCL activities a certain level of organisation is a requirement for the knowledge construction and convergence process. The students' organisation load depends on the level of the scripting of the CSCL activities. A highly scripted activity implies a high level of external organisation and a lower level of self and co-organisation. When the CSCL activity has a low level of external regulation, the students' requires a higher level of self and group organisation. CSCL approaches could then imply a high transactive cost in terms of organization that could reduce the time and efforts the students could devote to the knowledge construction and convergence process. In this paper, we analyse the impact of the organisation in the knowledge construction and convergence through a critical revision of the CSCL literature.
\end{abstract}

Keywords: Collaborative Learning, Computer Supported Collaborative Learning (CSCL), regulation, organisation, knowledge construction, knowledge convergence, Computer Learning Environment (CLE) 


\section{Regulación interior y exterior para apoyar la construcción y la convergencia de conocimientos en el aprendizaje cola- borativo asistido por ordenador}

\section{Resumen}

El Aprendizaje Colaborativo Asistido por Ordenador (ACAO) pretende facilitar los procesos de construcción y la convergencia del conocimiento colaborativos en los Entornos Virtuales de Aprendizaje. Durante las tareas ACAO, los estudiantes deben regular sus aprendizajes a nivel individual y colectivo. Estos procesos implican unos costes de organización relativa a la coordinación de la actividad con los compañeros de grupo y a la regulación interna y externa de esta actividad. Así pues, consideramos dos niveles en las actividades ACAO, un primer nivel que corresponde la construcción y convergencia del conocimiento y un segundo nivel que corresponde al coste de la organización. Asumimos que el tiempo y el esfuerzo dedicados a nivel de la organización no es un tiempo y esfuerzo dedicado al nivel de construcción y convergencia del conocimiento. Asumimos, pues, que las actividades ACAO requieren una organización de los procesos de construcción y convergencia del conocimiento. El nivel de organización necesaria para las actividades ACAO depende del nivel de guiaje de las actividades ACAO. Las actividades con un fuerte guiaje implican una fuerte organización externa de la actividad y un nivel más bajo de organización interna por la parte del estudiante. Cuando la actividad ACAO tiene un bajo nivel de regulación externa, los estudiantes necesitan un mayor nivel de regulación interna. En este segundo caso, las actividades ACAO pueden suponer un alto coste transactivo en términos de organización, lo que puede reducir el tiempo y esfuerzos dedicados a los procesos de construcción y convergencia de los conocimientos. En este artículo, analizamos el impacto de la organización en la construcción y la convergencia del conocimiento a partir de una revisión crítica de la literatura en el ámbito del ACAO.

Palabras Clave: Aprendizaje colaborativo, Aprendizaje Colaborativo Asistido por Ordenador (ACAO), regulación, organización, construcción del conocimiento, convergencia del conocimiento, Entorno Virtual de Aprendizaje (EVA). 


\section{Introduction}

Computer Supported Collaborative Learning (CSCL) aims to afford knowledge construction and convergence in the context of collective activities supported by Computer Learning Environments (CLE). For achieving the knowledge construction and convergence objectives, we consider both a knowledge perspective and an organisation perspective in the regulation of the CSCL activity. The knowledge perspective includes the self and coregulation necessary to achieve the knowledge construction and convergence. The organisation perspective includes the planning and monitoring of the students' task for succeding the learning tasks and subtasks and achieving their learning objectives.

From the knowledge perspective, the major concern in CSCL activities is the learning process and performance in collective situations. The CSCL activities have been considered as an opportunity to develop a positive interdependence (Johnson, Johnson, \& Holubec, 1998) and motivation (Järvelä \& Volet, 2004) and for developing higher-order cognitive skills (Stahl, 2007) among other benefits. We consider learning as the knowledge construction process produced during the learning tasks that are aligned with the pedagogical intentions of the activity (Newhouse, Trinidad, \& Clarkson, 2002). In long term collaborative tasks we assume that a group of students could achieve a certain degree of knowledge convergence, this is the process by which two or more people share mutual knowledge through social interaction due to transactivity that enables the discourse. Weinberger, Stegmann and Fischer (2007, p.1) define the knowledge convergence as the "learners becoming more similar to their learning partners with regard to the extent of their individual knowledge" and developping a shared knowledge meaning that "learners have knowledge on the very same concepts as their learning partners". Therebefore, the collaborative learning task requires a regulation activity from a perspective of knowledge an organization, including the planning and monitoring of the group members' activities during the task and the regulation of the learning process, both at the individual and the collective level. We distinguish the regulatory processes according to the agent who is regulating the collaborative learning task. We firstly discuss the distinction between self regulation and co-regulation, and then introduce the internal and external regulation differences.

The regulation process in collaborative learning activities includes a continuum of regulatory activities from "individual regulation within group" to "co-regulation as a group" 
(Volet, Summers \& Thurman, 2009, p. 129), which could regulate both the knowledge perspetive and the organisational perspective. At the individual level, Self Regulation of Learning (SRL) is considered as the learners' capacity to plan and monitor his/her activities for achieving the collaborative learning task goals within the context of his/her group. Boekaerts, Pintrich and Zeider (2000) define self-regulation as the "self-generated thoughts, feelings, and actions that are planned and cyclically adapted to the attainment of personal goals" (p. 14). Students who show higher SRL are metacognitively, motivationally, and behaviorally active participants in their own learning process (Zimmerman, 1989). From this perspective, metacognition is a part of the SRL process that provides monitoring and control of the learning process. Metacognitive skills are studied as individual differences that could explain the students' success in learning activities with minimal external regulation. On the other side, "students who lack metacognitive knowledge and skills are not able to direct their own learning" (Pintrich \& De Groot, 1990; Weinstein \& Mayer, 1986, in Boekaerts, 1999, p. 449). At the group level, co-regulation refers to the teammates' «constant monitoring and regulation of joint activity, which cannot be reduced to mere individual activity» (Vauras et al., 2003, p. 35). In collaborative based activities, Salonen, Vauras and Efklides (2005) consider the relevance of the students' awareness of the metacognitive process of the teammates' in the coregulation process.

Considering the long duration of CSCL activities (Reimann, 2009), we should consider the regulation process as a continuum of self and co-regulatory process that could be originated by the individuals within the group, or externally, by the teacher or the collaborative learning activity script. For this reason, we consider the distinction between the internal and external regulation agents that could initiate the regulatory process. Therefore, we assume internal and external agents in the regulation of the task. We assume that the organisation is internal when the learners and groups define the way to achieve the task. We lastly consider an external organisation when the way to organize the task is defined by the collaboration script or is regulated by teachers or other artificial agents.

In this CSCL literature review we aim to analyse the impact of internal and external regulation in relation to the knowledge construction and convergence process and stages. Firstly, we introduce the knowledge construction and convergence process, and the different levels of knowledge convergence in the collaborative learning activities; then we continue 
with the external and internal organisation in CSCL; and finally, we discuss the impact of such organisation in knowledge construction and convergence.

\section{Knowledge Construction and Convergence in CSCL}

Knowledge construction and convergence have been viewed as two separate processes. Knowledge construction implies the development of new knowledge for the individual or the group. Collaborative knowledge construction is suggested to occur in elaborated verbalisation in pedagogical discussions (Van-der Meijden, 2005). Despite the old interest in knowledge construction in the CSCL literature (Jermann \& Dillenbourg, 2003; Stahl, 2000), only the recent years, knowledge convergence characterisation has been considered as a major research objective in the field (Fischer \& Mandl, 2005; Jeong \& Chi, 2007; Monereo, 2009; Weinberger, Stegmann \& Fischer, 2007).

Beyond the individual process of the individual knowledge construction, we suggest that knowledge convergence in the group level occurs when two or more learners' activities have an impact on those of their partners, which then in turn have an impact on their own activities (Roschelle, 1996). For Monereo (2009) knowledge convergence is a process by which two or more people share mutual knowledge through social interaction due to transactivity that enables the discourse. Among the different proposals for explaining the levels of knowledge sharing, we follow the sharing knowledge levels of Monereo (2009) because it integrates other researchers' previous works (Dillenbourg, Järvelä, \& Fischer, 2009; Fischer \& Mandl, 2005; Weinberger, Stegmann \& Fischer, 2007). The different outcomes of the knowledge convergence process imply different levels of sharing. Based on Monereo's view these are consensus knowledge, common ground and common knowledge. These levels also indicate a specific measurable level of knowledge convergence (low, medium and high). Following Monereo, we incorporate these three levels of convergence as in the sharing levels in the next sections.

Sharing knowledge levels, interdependence and regulation requirements

In this section we start introducing the relation between the levels of sharing knowledge and the regulation requirements at each of these levels. For this objective, we consider 
three levels of sharing knowledge, their relation to the knowledge convergence and the regulation required to achive it. Secondly, after analysing the three levels of sharing knowledge and their regulation requirements, we introduce the interaction and interdependence concept for understanding the relation between the regulation and the knowledge convergence process.

Firstly, we consider three levels of sharing knowledge: the consensus knowledge is the lowest level in the knowledge convergence process, the common ground is the medium one, and the common knowledge is the highest level of knowledge convergence.

In the lowest level, consensus knowledge (Thompson \& Fine, 1999) implies a minimum convergence process or low level of convergence. Members of group can agree about the task rules or work conditions, but this is only a superficial stage of sharing, based on conventions. According to Volet, Summers \& Thurman (2009, p.129) this low-level of cognitive processing in the collaborative learning task "refer to sharing information, exchanging ideas, clarifying understanding, or providing definitions without evidence of transformation or integration with own mental representations". On this low level of sharing or consensus knowledge, the level of regulation required to achive this minimum convergence process is low.

In the medium level, common ground is defined by Bromme (2000) as a shared cognitive frame of reference. It refers to the interactive processes intended to create mutual understanding, knowledge, beliefs, and assumptions or repairing misunderstandings in a group (Baker, Hansen, Joiner \& Traum, 1999; Clark, Schreuder, \& Buttrick, 1983; Dillenbourg, 1999; Makitalo, Häkkinen, Leinonen, \& Järvelä, 2001). In order to achieve common ground, Johnson and Johnson (1994) suggest that learners need to exchange messages within the learning activities. Such messages can be explanations, relationships between previous and new knowledge and new activities, agreements, arguments as well as social messages such as encouraging other learners and active listening. In this way mutual understanding and shared meaning is created. Common ground implies the awareness about the knowledge of others, but this knowledge does not change one's own representations in order to share them with others (medium level of convergence). When this mutual knowledge is used to complement the necessary information to carry out a task (because each member has a portion of this information), the author uses the term distributed knowledge. In this case, group members often tend to neglect unshared information and resources. That could impoverish the global knowl- 
edge of the group (Fischer \& Mandl, 2005). For achieving this medium level of sharing knowledge, the level of internal/external regulation should promote the learners' exchanges allowing them to understand their teammates' knowledge.

In the highest level, common knowledge is the knowledge known by all group participants (Jeong \& Chi, 2007). It refers to the similarities in representation of knowledge itself, and requires processing the contribution of others in depth. Volet, Summers \& Thurman (2009, p.129) consider that a "high-level content processing, and not merely sharing information" requires and effective co-regulatory activity.

After analyzing the three levels of knowledge convergence, we introduce the relation between the knowledge convergence and the regulatory processes according to the consideration of two different aspects under the term knowledge convergence, process convergence and outcome convergence, proposed by Fischer, Bruhn, Gräsel and Mandl (2002). Process convergence refers to organizational interaction and outcome convergence to learners' reciprocal influence leading to increased group cognitive similarity. In particular, they support that knowledge convergence is closely linked to interdependence. Interdependence suggests that each individual's cognitive responses are influenced by the interaction in which he or she is a participant. Therefore, such reciprocal influence of the collaborators leads to an increased similarity of the cognitive responses within the group, and thus leads to knowledge convergence (Ickes \& Gonzales, 1996). Teasley and colleagues (2008) considers the joint construction, intersubjectivity and reasoning transactions to propose the concept of cognitive convergence in the collaborative learning activities. Communication and coordination are highlighted by Ellis, Gibbs and Rein (1991). Romero and colleagues (2009) were based on Ellis and collaborators to propose the importance of organisation and coordination in knowledge convergence studied within long term CSCL activities and applied in online education.

Overall, students' interdependence promotes interaction, which in turn needs organisation in order to facilitate knowledge construction and convergence. Next, we introduce different aspects of this organisation and their impact in CSCL.

\section{Organisation in CSCL}

In the CSCL activities, we consider a knowledge perspective and an organisation perspective in the execution of the activity. Aflter introducting the knolwedge perspective in the 
previous section, we introduce in this section the organisation perspective. From a time management and planning perspective, organisation could be initially described as the planning and regulation of the individual and group activities to achieve a goal or task. We consider the regulation process within the organisation objectives of the learning task. This refers to the planning and monitor of the organisation activity developed by the students, at the individual and collective level, to achieve the collaborative learning task objectives. In this paper we will use the term organisation to refer both the activities of planning towards a learning task as well as the update of the plan and the activities in order to achieve the goals and tasks. In a CSCL task, the main agent involved in the organisation and the regulation activity is the learner, who should achieve his learning objectives and complete the learning task.

Apart of the learner herself, we also consider the students' team-mates, the teacher, the CLE and the script of the task, as organisation and regulation agents in the CSCL task development. Considering these agents we propose two levels of organisation, the internal and external. The internal organisation includes both the individual and the group organisation. Individual organisation includes the learner developing his self-organisation and self-regulation activities. The group organisation, considered also as coordination, refers to the collective level of the organisation, group regulation or co-regulation. In the second level, external organisation includes script-based organisation and regulation, the teacher guidance and all other external organisation and regulation agents.

The internal and external levels of organization are interdependent. Based on the degree of the detailed description and the rigidity of the external script, another part of the organisation is regulated internally by the group and the students. Before analysing the impact of the degree of the individual, group and external organisation, we describe below each of these organisation levels.

\section{Internal organisation}

Internal organisation includes both the individual and group organisation made by the learner, individually, or the group of learners, collectively. The individual organisation includes the self-organisation and self-regulation processes; online communication and collaboration requires such competencies and appropriate tools in order to achieve individual and group targets. According to Moguel, Tchounikine and Tricot (2008), self-organisation re- 
quires ability to observe one's self, this is a metacognitive ability. In addition, such selforganisation needs to occur within a group to support a pattern of collective arrangement (Tchounikine, 2007). Such self-organisation and regulation processes aim at self-diagnose in order to enable correcting actions in the collaboration management cycle. Within the different stages of the collaboration process, interactions need to be evaluated and regulated with respect to a desired state, and remedial actions may be proposed to reduce discrepancies (Jermann, Soller, \& Muehlenbrock, 2001). The authors suggest that such moderated activities are also needed to structure the group itself and the tasks by encouraging interaction towards a desired direction. Such internal group organisation requires the capacity of the students to plan and regulate their own learning processes. In the collective level, group organisation includes the co-organisation, cooperation and co-regulation.

While discussing group cognition in CSCL, Stahl (2006) suggested that other than the individual, research needs to focus on the group level as well. It has been reported by Cakir, Zemel and Stahl (2008) that such group organisation is a problem and a central issue in CSCL. The researchers propose three aspects of group organisation in problem solving situations: group interaction, weaving the social fabric and creating the actual problem solving space. This group organisation requires the students' capacity to plan and regulate their own learning process. Moguel, Tchounikine and Tricot (2008), based on Bardrams' model (1998), have addressed this difficulty as the individuals need to perceive breakdowns early and even predict them to avoid discrepancies in group collaboration and sustain the group dynamics. Therefore, the team-members need to conceptualise and reconceptualise their own organisation and interaction in relation to their team-members, objects and means of work. In other words, both self- and group-organisation and regulation are affected by intertwined and complex factors which are difficult to address in their total and, according to Tchounikine (2007), very difficult to predict.

\section{External organisation}

External organization includes the use of detailed planning (i.e. script) describing the way students have to collaborate: task distribution or roles, turn taking rules, work phases, deliverables, etc. (Dillenbourg \& Jermann, 2007). Dillenbourg (2002, p.1) suggest that a script is " a set of instructions prescribing how students should form groups, how they should interact and collaborate and how they should solve the problem". This instruction provides an 
external organisation and regulation of the task. In the context of collaborative learning, the collaboration scripts describe the sequence of phases, each characterized by the following five attributes: type of task to be accomplished, group formation (and composition), distribution of the task within and among groups, type and mode of interaction (e.g., co-located vs. remote, synchronous vs. asynchronous, text-based vs. voice-based, etc.), and timing of the phase (Dillenbourg, 2002). Micro-scripts are dialogue models, mostly argumentation models, which are embedded in the environment and which students are expected to adopt and progressively internalize (Dillenbourg \& Hong, 2008). Macro-scripts are pedagogical models, i.e. they model a sequence of activities to be performed by groups. For instance, argumentation can be triggered by collecting students' opinions and pairing students with conflicting opinions (Dillenbourg \& Hong, 2008).

\section{Interdependence of internal and external organisation}

The internal and external organisation levels may be considered interdependent in the purpose of the group coordination for achieving the collaborative learning activity. When the external organisation is low, the internal organisation requirements are higher, and vice versa. Before discussing the correct level of internal and external organisation, analysis of the impact of the two extreme situations is needed: a low external organisation requiring a high internal organisation, and a high external organisation reduces the need and the possibilities of internal organisation.

In the first case, in tasks with a low level of external organisation, or minimal guidance, students have the responsibility to organise the activity in the individual and group level (self- and co-organisation). A high level of internal organisation supposes that great effort is required to plan and regulate their learning task, reducing the time spent on the knowledge construction and convergence process. Kirschner, Sweller and Clark (2006) evaluate the consequences of a low level of external organisation in terms of high transactive costs reducing the learning achievements of the learners. Poorly externally regulated CSCL could be considered as underegulated or underscripted. Considering the human's limited cognitive capacity, Kirschner, Paas and Kirschner (2009) suggests that poorly designed instruction does not contribute to learning because the increase of the extraneous cognitive load. This load reduces the intrinsic cognitive load that is directly related to the effective learning activity (Sweller, van Merrienboer \& Paas, 1998). In externally underregulated learning activities, students face a 
high transactive cost and difficulties such as temporal coordination (Romero, 2010). In this context, the cooperation efforts could be excessive and conduct to fewer knowledge exchanges during the activity. In this situation, learners need to be equipped with a high level of organization skills to achieve the learning objectives (Drexel, 2010). Nevertheless, we should consider the students' individual differences in their SRL and metacognitive development (Winne, 2002), their volitional control (Bartels, Magun-Jackson, \& Kemp, 2009), their learning styles (Vermunt, 1992), their prior domain knowledge (Alexander, 2003; Moos \& Azevedo, 2008, 2009), their representation of the task (Castelló, Iñesta \& Monereo, 2009) among other individual differences for understanding their possibilities to succeed in lowlevel externally regulated activities. According to these authors, low-level externally regulated activities can be suitable for students with a high level of self and co-regulation, cognitive deep processing learning style, and higher levels of prior domain knowledge. We should then identify the students' differences at the individual and the collective level for considering the appropriate degree of external regulation.

At the opposite situation, when the level of external regulation is excessive we are on an overregulated learning situation. When the overregulation is produced by an excessive script we talk about an overscripted activity (Dillenbourg, 2002), introducing the risk of reducing the interaction dynamics for the knowledge construction and convergence process on the individual and the group level. Bokaerts (1999, p.450) analyses the risks of too much external regulation even in the contexts of the students' with poor self-regulatory skills. These students could have an incorrect feeling of control when the external regulation provided by the teacher allows them to achieve the task, but they reduce the achievement in contexts without external regulation of the teacher. Instead of developing their own SRL abilities, too much external regulation could leads the students to rely in their teachers' regulation (Weinert, Schrader \& Helmke, 1989 in Bokaerts, 1999). 


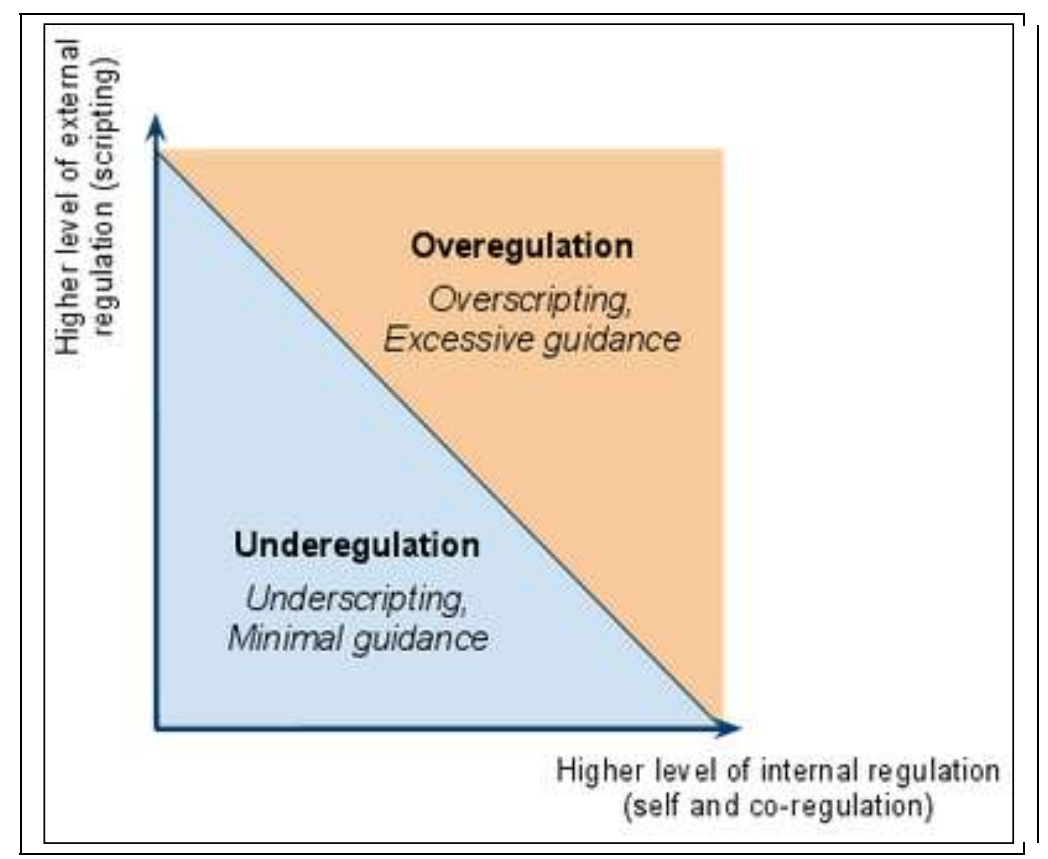

Figure 1. Overscripting and undescripting depending on the level of external and internal regulation

The proposed model for the understanding of the relation between the external and internal levels of regulation and their risks as over or under regulation are represented in Figure 1. The more the need for external regulation, the more detailed scripting is needed, and consequently, less internal self- and co-regulation is feasible. On the contrary, the less the need for external regulation, the less detailed scripting is needed, and consequently, more internal self- and co-regulation is feasible. Furthermore, the degree of scripting of the CSCL activities appears to be of extreme importance. In the first case there is the risk of underscripting and in the second case there is the danger of overscripting.

\section{Tension between Higher level of External - Internal Regulation}

The correct level of external and internal regulation is different according to the organisation and regulation capacities of the learners, at the individual and collective level. It also depends on the nature of the task, the moment of the task, the degree of expertise of the learners in the subject and the heterogeneity of all these aspects at the collective level. To complicate even more the equation, such external regulation requirements and individual and group regulation capabilities could change during the task duration. Therefore, the concepts of script fading (Strijbos \& Weinberger, 2010; Wecker \& Fischer, 2007) and scaffolding (Pea, 
2004) suggest the progressive reduction of the external guidance. As a result, the definition of the degree of external and internal organisation and regulation is related to the authentic contexts where the task is situated. Also, task organisation needs to be flexible and adaptable longitudinally to the internal organisation and regulation needs of the learners and the group. Furthermore, the consideration of on-demand external regulation could be a solution for avoiding over scripting and the risks of a rigid low script.

\section{Impact of Internal and External Organisation in Knowledge Construction and Conver- gence}

The degree of external organisation, and the subsequent requirement of internal organisation, has an impact in the knowledge construction and convergence process. According to Kirschner, Sweller \& Clarck (2006) the internal organisation activity is considered as a transactive cost, without a specific pedagogical value. On one hand, we could consider the possibility to reduce the internal organisation responsibility of the students, and introduce a high level of external organisation. However, this external regulation will have an impact on the temporal flexibility of the task and the regulation skills deployed by the students. On the other hand, a high level of internal organisation could lead to an excessive cost in the internal organisation activity at the students level and reduce the time devoted to the knowledge construction and convergence process. The development of SRL skills could help the students to regulate this high level of internal organisatio requirement, allowing him/her and the group to reduce the time devloted to the organisation activity and focus on the knowledge construction and convergence process.

Defining the correct level of internal and external organisation will depend on the context and should consider a level of organisation aiming to facilitate the students' interaction that leads to the knowledge construction and convergence. As previously proposed, a certain degree of activities organisation is defined by the script aiming at supporting and facilitating knowledge construction and convergence. For Weinberger (2004) the process that aims at outcome convergence has an important impact on knowledge convergence. For the authors, process convergence has an impact on learning because, on one hand, learners communicate individual knowledge and, on the other hand, learning partners internalise these knowledge concepts. Also, outcome convergence indicates to what extent learning partners are able to apply the shared knowledge in the individual condition. Based on the knowledge construction 
and convergence objective, the level of internal and external organisation should be defined by the type of tasks and subtasks, aiming to reduce progressively the external regulation requirements in order to develop the learners' internal regulatory skills.

\section{Conclusion}

This paper aimed at addressing the importance of internal regulation, this is self- and co-regulation of collaborative group activities; and also external regulation (teacher and script based) to support knowledge construction and convergence in Computer Supported Collaborative Learning (CSCL). When collaborating in the purpose of learning, individuals come from different levels of SRL skills and metacognition development, different learning styles and different prior domain knowledge, among other individual differences. The level of external regulation they require for achieving the expected knowledge construction and convergence process should be adapted according to the type of task and the students' individual differences. Is essential that collaborative activities are designed and scripted depending on students' ability to regulate themselves in order to achieve self- and group-autonomy in their activities, and achieve the highest level of sharing knowledge, the common knowledge. As educators we need to work on the thin line between high and low level of external regulation that could be required, at the individual and the collective level, by the students with higher regulation abilities, to achieve the collaborative learning task. At the organisational level, the internal regulation related to organisational aspects that are not aligned with the learning objectives, should be reduced to allow the students to focus their cognitive load to the internal regulation of the knowledge perspective of the collaborative learning task.

At the knowledge perspective, the level of external regulation should be designed with the objective of a progressive transfer from the external regulation towards the internal regulation abilities, allowing the learners' to focus on the knowledge construction and convergence and to develop their self and co regulation of learning abilities. Considering the complex conditional factors within authentic learning contexts, the educators are needed to adjust this level of external regulation within the duration of the learning activities to avoid both the excess of external regulation (overregulation) and the lack of it (underregulation) at the individual and collective level. This adjustment should be dialectical, considering the progressive development of the student's internal regulation abilities for overcoming the underregulation situations, and the students' developement of help seeking strategies for allowing them to identify 
the excess of external regulation and negotiate its level with the teacher. Both of these aspects should be considerated as competencies that will allow the learner to become a more autonomous lifelong learner, prepared for achieving the knowledge construction and convergence process in collaborative learning tasks activites with different levels of internal and external regulation.

\section{References}

Alexander, P. A. (2003). The development of expertise: The journey from acclimation to proficiency. Educational Researcher, 32(8), 10-14.

Baker, M., Hansen, T., Joiner, R., \& Traum, D. (1999). The role of grounding in collaborative learning tasks. In P. Dillenbourg (Ed.), Collaborative learning: Cognitive and computational approaches (pp. 31-63). Oxford: Pergamon.

Bardram, J. E. (1998). Collaboration, Coordination, and Computer Support: An Activity Theoretical Approach to the Design of Computer Support for Cooperative Work. Doctoral Dissertation, University of Aarhus. Available as Daimi Technical Report, PB533.

Bartels, J.M., Magun-Jackson, S., \& Kemp, A.D. (2009). Volitional regulation and selfregulated learning: An examination of individual differences in approach-avoidance achiement motivation. Electronic Journal of Research in Educational Psychology, 7, 605-626.

Boekaerts, M (1999). Self-regulated learning: where we are today. International Journal of Educational Research. v31. 445-475.

Boekaerts, M., Pintrich, P. R., \& Zeider, M. (2000). Handbook of self -regulation. San Diego. Calif.: Academic Press.

Bromme, R. (2000). Beyond one's own perspective: the psychology of cognitive interdisciplinarity. In P. Weingart \& N. Stehr (Eds.), Practicing interdisciplinarity (pp. 115133). Toronto, Canada: University of Toronto Press. 
Çakır, M.P., Zemel, AL. \& Stahl, G. (2008). The joint organization of interaction within a multimodal CSCL medium. International Journal of Computer-Supported Collaborative Learning, 4(2), 115-149.

Castelló, M., Iñesta, A. \& Monereo, C. (2009). Towards self-regulated academic writing: an exploratory study with graduate students in a situated learning environment. Electronic Journal of Research in Educational Psychology, 9 (3).

Clark, H. H., Schreuder, R., and Buttrick, S. (1983). Common ground and the understanding of demonstrative reference. Journal of Verbal Learning and Verbal Behavior, 22, 245258.

Dillenbourg, P. (1999) What do you mean by collaborative learning?. In P. Dillenbourg (Ed), Collaborative-learning: Cognitive and Computational Approaches. (pp.1-19). Oxford: Elsevier.

Dillenbourg, P. (2002). Over-scripting CSCL: The risks of blending collaborative learning with instructional design. In, P. A. Kirschner (ed.), Three worlds of CSCL. Can we support CSCL? (pp. 61-91). Heerlen, NL: Open Universiteit Nederland.

Dillenbourg, P., \& Hong, F. (2008). The mechanics of CSCL macro scripts. International Journal of Computer-supported Collaborative Learning, 3(1), 5-24.

Dillenbourg, P., Järvelä, S., \& Fischer, F. (2009). The evolution of research on computersupported collaborative learning: from design to orchestration. In N. Balacheff, S. Ludvigsen, T. de Jong, T., A. Lazonder \& S. Barnes (Eds), Technology-Enhanced Learning. Principles and products (p. 3-19). Heidelberg: Springer.

Dillenbourg, P. \& Jermann P. (2007). Designing Integrative Scripts. In: Fischer, F., Kollar, I. Mandl, H., Haake, J.M. (Eds.), Scripting Computer-Supported Collaborative Learning: Cognitive, Computational and Educational Perspectives, Computer-Supported Collaborative Learning Series, Vol. 6, Springer.

Drexel, W. (2010). The networked student model for construction of personal learning environments: Balancing teacher control and student autonomy. Australasian Journal of Educational Technology (AJET) 2010, 26(3), 369-385.

Ellis, C. A.; Gibbs, S. J. and Rein, G. L. (1991) Groupware - some issues and experiences. Comm. of the ACM, 34(1) 38-58. 
Fischer, F., Bruhn, J., Gräsel, C., \& Mandl, H. (2002). Fostering collaborative knowledge construction with visualization tools. Learning and Instruction, 12, 213-232.

Fischer, F., \& Mandl, H. (2005). Knowledge convergence in computer-supported collaborative learning: The role of external representation tools. Journal of the Learning Sciences, 14(3), 405-441.

Ickes, W. \& Gonzalez, R. (1996) "Social” cognition and social cognition. In J. L. Nye \& A. M. Broker (Eds.), What's social about social cognition? (pp. 285-309). Thousand Oaks, CA: Sage.

Järvelä, S. \& Volet, S. (2004). Motivation in Real-Life, Dynamic, and Interactive Learning Environments: Stretching Constructs and Methodologies. Journal European Psychologist, 9(4), 193-197.

Jeong, H. \& Chi, M.T.H. (2007). Knowledge convergence and collaborative learning. Instructional Science, 35(4), 287-315.

Jermann, P., \& Dillenbourg, P. (2003). Elaborating new arguments through a cscl scenario. In G. Andriessen, M. Baker, \& D. Suthers. (Eds.), Arguing to learn: confronting cognitions in computer-supported collaborative learning environments. ComputerSupported Collaborative Learning Series. Amsterdam: Kluwer.

Jermann, P., Soller, A. \& Muehlenbrock, M. (2001). From Mirroring to Guiding: A Review of State of the Art Technology for Supporting Collaborative Learning. In the European Conference on Computer-Supported Collaborative Learning EuroCSCL-2001, Maastricht: Netherlands.

Johnson, R. T. \& Johnson, D. W. (1994). An overview of cooperative learning. In Thousand, J., Villa, A., \& Nevin, A. (Eds), Creativity and Collaborative Learning. Baltimore, MD: Brookes Press.

Johnson, D., Johnson, R. \& Holubec, E. (1998). Cooperation in the classroom. Boston: Allyn \& Bacon.

Kirschner, F., Paas, F., \& Kirschner, P. (2009). Individual and group-based learning from complex cognitive tasks: Effects on retention and transfer efficiency. Computers in Human Behavior, 25, 306-314.

Kirschner, P. A., Sweller, J., \& Clark, R. E. (2006). Why Minimal Guidance during Instruction Does Not Work: An Analysis of the Failure of Constructivist, Discovery, Prob- 
lem-Based, Experiential, and Inquiry-Based Teaching. Educational Psychologist, 41(2), 75-86.

Mäkitalo, K., Häkkinen, P., Leinonen, P., \& Järvelä, S. (2002). Mechanisms of common ground in casebased web discussions in teacher education. Internet and Higher Education, 5, 247-256.

Moguel, P., Tchounikine, P. \& Tricot, A. (2008). Analyzing Learners' Self-organization in Terms of Co-construction, Co-operation and Co-ordination. Intelligent Tutoring Systems, Lecture Notes in Computer Science, 5091, 743-745

Monereo, C. (2009). Knowledge convergence. State of the Art. Internal report available on http://cat-cscl.eu.

Moos, D.C., \& Azevedo, R. (2009). Self-efficacy and prior domain knowledge: To what extent does monitoring mediate their relationship with hypermedia? Metacognition and Learning, 4(3), 197-216.

Moos, D.C., \& Azevedo, R. (2008). Self-regulated learning with hypermedia: The role of prior domain knowledge, Contemporary Educational Psychology, 33, 270 - 298.

Newhouse, C.P., Trinidad, S. \& Clarkson, B. (2002). Quality Pedagogy and Effective Learning with Information and Communications Technologies (ICT). A review of the literature report. A Teacher Professional ICT Attributes Framework - Outcomes, Guidelines, Equipment and Processes. Perth, Western Australia: Specialist Educational Services.

Pea, R. D. (2004). The social and technological dimensions of "scaffolding" and related theoretical concepts for learning, education and human activity. The Journal of the Learning Sciences, 13(3), 423-451.

Pintrich, P. R., \& De Groot, E. V. (1990). Motivational and self-regulated learning components of classroom academic performance. Journal of Educational Psychology, 82, $33\} 40$.

Reimann, P. (2009) Time is precious: Variable and event-centred approaches to process analysis in CSCL research. ijcscl 4 (3), 239-257.

Romero, M. (2010). Gestion du temps dans les Activités Projet Médiatisées à Distance. Thèse de Doctorat en cotutelle européenne. Université de Toulouse (CLLE-LTC UMR 
CNRS 5263) et Universitat Autònoma de Barcelona (SINTE SGR 2009 134). Saarbrücken: Editions Européenes Universitaires.

Romero, M., Lambropoulos, N., Culwin, F., Marine, C., Castello, M \& Monereo, C. (2010). Collaboration Awareness Tool (Euro-CAT) for communication, coordination and knowledge convergence in Computer Supported Collaborative Learning (CSCL). In the Proceedings of the Online EDUCA, 2-4 December, 2009, Berlin, Germany.

Roschelle, J. (1996). Learning by collaborating: Convergent conceptual change. In T. Koschmann (Ed.), CSCL: Theory and practice of an emerging paradigm (pp. 209-248). Mahwah, NJ: Lawrence Erlbaum Associates, Inc.

Salonen, P.; Vauras, M.; Efklides, A.(2005) Social Interaction--What Can It Tell Us about Metacognition and Coregulation in Learning? European Psychologist, 10(3), 199-208. Stahl, G. (2000). Collaborative information environments to support knowledge construction by communities. AI \& Society, 14, 1-27.

Stahl, G. (2006). Group cognition: Computer support for building collaborative knowledge. Cambridge, MA: MIT. Retrieved from http://GerryStahl.net/mit/. Last access 20/09/2010.

Stahl, G. (2007). Meaning making in CSCL: Conditions and preconditions for cognitive processes by groups. Paper presented at the international conference on Computer Support for Collaborative Learning (CSCL 2007), New Brunswick, NJ.

Strijbos, J. W., \& Weinberger, A. (2010). Emerging and scripted roles in computer-supported collaborative learning. Computers in Human Behavior, 26, 491-494.

Sweller, J., van Merrienboer, J., \& Paas, F. (1998). Cognitive architecture and instructional design. Educational Psychology Review, 10, 251-296.

Tchounikine P. (2007). Directions to acknowledge learners' self organization in CSCL macroscripts. In: Groupware: Design, Implementation and Use, LNCS n4715, Haake J.M., Ochoa S.F., Cechich A. (eds), Springer Berlin / Heidelberg, p. 247-254 .

Teasley, S.d., Fischer, F., Weinberger, A., Stegmann, K., Dillenbourg, P., Kapur, M. \& Chi, M. (2008). Cognitive convergence in collaborative learning. Proceedings of the 8 th international conference on International conference for the learning sciences. Utrecht, The Netherlands, Pages 360-367. 
Thompson, L., \& Fine, G.A., (1999). Socially shared cognition, affect, and behavior: a review and integration. Personality and Social Psychology Review, 3(4), 278-302.

Van der Meijden, H. (2005). Knowledge construction through CSCL: Student elaborations insynchronous, asynchronous, and three-dimensional learning environment. Unpublished doctoraldissertation, University Nijmegen, the Netherlands.

Vauras, M., Iiskala, T., Kajamies, A., Kinnunen, R., \& Lehtinen, E. (2003). Sharedregulation and motivation of collaborating peers: A case analysis. Psychologia, 46(1), 19-37.

Vermunt, J.D.H.M. (1992). Learning styles and guidance of learning processes in higher education. Amsterdam: Lisse Swets and Zeitlinger.

Volet, S.E., Summers, M., \& Thurman, J. (2009) High-level co-regulation in collaborative learning: How does it emerge and how is it sustained? Learning and Instruction, 19, 128-143.

Wecker, C., \& Fischer, F. (2007). Fading scripts in computer-supported collaborative learning: The role of distributed monitoring. In the Proceedings of Computer Supported Collaborative Learning CSCL 2007, New Brunswick, New Jersey, USA, 764-772.

Weinberger, A. (2004). Knowledge convergence in computer-mediated learning environments: Effects of collaboration scripts. Paper presented in the Annual Meeting of the American Educational Research Association (AERA 2004), San Diego, CA. Retrieved from http://hal.archives-ouvertes.fr/docs/00/19/74/09/PDF/Weinberger-Armin2004b.pdf. Last access 20/09/2010.

Weinberger, A., Stegmann, K. \& Fischer, F. (2007). Knowledge convergence in collaborative learning: Concepts and assessment. Learning \& Instruction, 17, 416-426.

Weinert, F.E., Schrader, F-W. \& Helmke, A. (1989). Quality of instruction and achievement outcomes. International Journal of Educational Research, 13(8), 895-914.

Weinstein, C. E., \& Mayer, R. E. (1986). The teaching of learning strategies. In M. Wittrock, Handbook of research on teaching (pp. 315\}327). New York: Macmillan

Winne, P. (1996) A metacognitive view of individual differences in self-regulated learning, Learning and Individual Difference, 8, 327-53.

Zimmerman, B. J. (1989). A social cognitive view of self-regulated academic learning. Journal of educational psychology, 81(3), 329-339. 
Margarida Romero et al.

[This page intentionally left blank] 